\title{
Cultura escolar, cultivo de corpos: Educação Physica e Gymnastica como práticas constitutivas dos corpos de crianças no ensino público primário de Belo Horizonte $(1906-1920)^{*}$
}

\author{
Tarcísio Mauro Vago**
}

\begin{abstract}
RESUMO
Problematiza-se, neste trabalho, o movimento de afirmação de uma nova cultura escolar em Belo Horizonte nas duas primeiras décadas do século $\mathrm{XX}$, especialmente após a reforma do Ensino Primário promovida pelo governo mineiro em 1906. Nela, depositou-se a esperança de realizar uma "revolução de costumes" nas crianças, especialmente as filhas de populações pobres, procurando, ao mesmo tempo, destruir seus hábitos de origem e implantar-lhes maneiras consideradas civilizadas. Mais que instruir, era preciso educar. Educação que se traduziu também como cultivo dos corpos: muitos foram os dispositivos mobilizados para realizar uma pretendida "educação physica" das crianças, presentes na legislação do ensino; nas maneiras de organizar e ocupar os espaços; na distribuição dos tempos escolares; nas diferentes disciplinas dos programas de ensino; na obsessão pela higiene; na inspeção médica; nos rituais escolares; na aproximação com as práticas de trabalho; e, ainda, nos muitos cuidados que lhes dedicavam as Diretoras e professoras. Acompanhando mais detidamente o enraizamento escolar da "Gymnastica", a partir dos ordenamentos legais prescritos no período e dos relatórios produzidos pelos agentes escolares, buscou-se evidências do processo de instituição de seu campo disciplinar, indicando-se que seu ensino foi representado e orientado sob o primado da correção e constituição dos corpos das crianças, tidos como disformes e desalinhados. Os impasses e precariedades desse processo não impedem de ver, no entanto, o investimento de uma época

* Este texto é um breve resumo de minha Tese de doutorado, com o mesmo título, aprovada na Faculdade de Educação da USP, sob orientação da Professora Dra. Marta Chagas de Carvalho (USP), tendo servido de base para apresentação na seção de defesa, realizada em 6 de dezembro de 1999. A pesquisa contou com financiamento do CNPq.

** UFMG, Doutor em Educação. tata@cp.ufmg.br
\end{abstract}


sobre o corpo das crianças, no âmbito da escola.

Palavras-chave: cultura escolar, corpo, educação física.

\begin{abstract}
In this work we studied the process involved in the establishment of a new school culture in Belo Horizonte during the first two decades of the 20th century, especially after the launching of the reform of elementary school by the government of Minas Gerais state in 1906. This reform was undertaken waiting for children's habit revolution, especially those from poor populations wich would lead, at the same time, to the destruction of their original habits and to the establishment of "civilized habits". The main idea was based on the premisse that instructing children is more important than educating them. Education has also been translated as "body cultivation": many approaches were used to perform the desired "physical education" of the children, which were reflected in the teaching laws; in the way of organizing and using the rooms; in the distribution of school times; in the different subjects of teaching programs; in the implementation of strict hygiene habits; in medical inspection; in the school rituals; in the introduction of work practices and in the care dedicated to the children by principals and teachers. By analysing the establishment of the "Gymnastic" in the school, based on laws from that period and reports made by school agents, this study searched for evidence of the implementation of this subject field. The present work indicates that teaching was represented and orientated in order to correct and work on the constitution of children's bodies, which was considered to be deformed and disarrayed. Despite the impasses and precarities of this process, it is still relevant to demonstrate the importance of an investiment made at a period of time focused on children's bodies at school.
\end{abstract}

Key-words: school culture, body, physical education.

O planejamento e a edificação de Belo Horizonte, na década seguinte à proclamação da República, foram orientados pelas novas experiências sociais e urbanas vividas ao final do século XIX, com uma concepção do social e do cultural, que, ao mesmo tempo, enfatizava a importância da ciência e do progresso e se confrontava com o que passou a ser considerado práticas retrógradas e tradicionais de se pensar as relações dos indivíduos com a cidade. ${ }^{1}$

1 VEIGA, C. G. Projetos urbanos e projetos escolares - aproximação na produção de representações de educação em fins do século XIX. Belo Horizonte: UFMG, Faculdade de Educação, 1997 (digitado). 
Arrasadoras foram as representações produzidas sobre os habitantes do arraial sobre o qual construiu-se a cidade. Longe estavam de ser considerados "bonitos e elegantes". ${ }^{2}$ Ao contrário, cronistas da época escreviam que "o tipo geral" daquele povo era "doentio; magros, amarelos, pouco desempenados na maioria, havendo uma grande proporção de defeituosos, aleijados e raquíticos"; 3 constituíam um povo "tosco", "esgrouvirado das costas", "amarelo", "indolente", "provinciano", "ignorante", "vadio", "de reputação duvidosa", "turbulento", "pernicioso", "de hábitos suspeitos" e "baderneiros". 4

Sobre tais representações, a nova capital de Minas Gerais foi arquitetada e construída como ruptura com o passado, de que Ouro Preto Preto era símbolo. Em tudo ela deveria lembrar, refletir, reproduzir e fixar os princípios republicanos de organização da sociedade. Nessa "cidade modelar" não caberia "nem o tortuoso, nem o estreito, nem o baixo, nem o deselegante". 5 Sua planta simétrica, alinhada, seria ela mesma uma espécie de "panóplia corretora"6 a endireitar seus habitantes, antigos e novos. O traçado exigia, impunha modelava - uma outra corporeidade.

Os tempos que se seguiram à sua inauguração, no entanto, frustraram expectativas: o previsto não se materializava naturalmente. Belo Horizonte não escapou da instabilidade econômica e política do regime republicano, que se materializava em suas ruas.

Os problemas vividos nas décadas seguintes à proclamação da República fortaleceram a crença de intelectuais e políticos republicanos mineiros de que a construção de uma Nação e de um Estado prósperos dependia, em boa medida, de se lançar mão da escola como recurso civilizatório. O cenário tornou-se propício para a afirmação e legitimação de uma pedagogia moderna e científica, ${ }^{7}$ centrada na realização da tríade "educação moral, intellectual e physica", a começar pelas crianças.

2 PENNA, A. D. Belo Horizonte: um espaço infiel. Varia Historia, Belo Horizonte, n. 18, p. 101-121, set. 1997.

3 CARDoso Silva, V. A. Crônicas de Belo Horizonte. Varia Historia, Belo Horizonte, n. 18, set. 1997; citando o cronista Alfredo Riancho, em crônica de 1894.

4 VEIGA, op. cit., aludindo a representações da Comissão Construtora de Belo Horizonte.

5 PENNA, op. cit.

6 Estou, aqui, inspirando-me em trabalho de Georges Vigarello (Cf. VIGARELLO, G. Panóplias corretoras. In: SANT'ANNA, D. B. (Org.). Políticas do corpo. São Paulo: Estação Liberdade, 1995.).

7 Cf. CARVALHO, M. M. C. Quando a história da Educação é a história da disciplina e da higienização das pessoas. In: FREITAS, M. C. (Org.). História social da infância no Brasil. São Paulo: Cortez, 1997a. 
A pretensão exigia um novo modelo escolar, que começou a se materializar com a reforma do ensino primário promovida em 1906 pelo governo mineiro, cuja grande novidade consistiu na instituição dos Grupos Escolares, a forma escolar que já estava difundida nos EUA e em países europeus. Com eles, esperava-se realizar o que as Escolas Isoladas até então existentes, tidas por precárias, não poderiam conseguir: provocar o que o inspetor escolar José Rangel consagrou como "uma verdadeira revolução de costumes" ${ }^{8}$ no seio da população. Foi essa ambição que envolveu Minas Gerais em um movimento de afirmação de uma nova cultura escolar, nas duas primeiras décadas do século XX.

Doravante, da escola que se instituía naquele período em Minas Gerais, particularmente em Belo Horizonte, não mais se esperava que ensinasse apenas a ler, escrever e contar. Muito mais que instruí-las nesses rudimentos, o modelo escolar que surgia encarnou a esperança de intervir o quanto mais profundo possível na educação das crianças, especialmente as provenientes de populações pobres: civilizá-las, arrancá-las do estado de indigência, imporlhes uma transfiguração que faria delas potenciais construtores da prosperidade do Estado. Mais que instruir, era preciso educar; e, ainda, dar uma profissão. Impor novos hábitos culturais às crianças e ao mesmo tempo prepará-las para a sua inserção nas práticas do trabalho eram duas pretensões de primeira grandeza atribuídas à escola. Sua necessidade foi produzida, dentre outros motivos, como recurso para sair da crise e construir uma República e uma economia prósperas.

$\mathrm{Na}$ capital mineira, a afirmação dessa nova cultura escolar deu-se também porque mesmo que a cidade tenha sido planejada para que tudo fosse "tão claro, reto, visível", os seus habitantes "confundiam, ou teimavam em confundir, as referências claramente assinaladas", e então a escola constituiu "uma das faces educadoras e civilizadoras das populações pobres", como escrevem Cynthia Greive e Luciano Mendes Faria Filho.

Nessa cultura escolar não haveria lugar para o saber produzido pelas populações pobres, desqualificado para dar lugar ao conhecimento consagrado como necessário à educação racional dos habitantes da cidade moderna, de um Estado e de uma Nação que aspiravam ao progresso. Esse conhecimento deveria se materializar no programa prescrito legalmente para o ensino primário, que incluía as disciplinas de "Leitura, Escripta, Lingua Patria, Arith-

8 José Rangel, inspetor escolar em Juiz de Fora (MG). (Cf. Arquivo Público Mineiro.

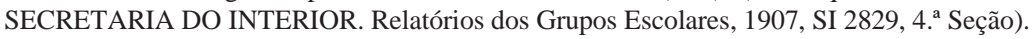

9 Cf. VEIGA, C. G.; FARIA FILHO, L. M. Belo Horizonte: a escola e os processos educativos no movimento da cidade. Varia Historia, Belo Horizonte, n. 18, p. 215, set. 1997. 
metica, Geographia, Historia do Brasil, Instrucção Moral e Civica, Geometria e Desenho, Historia Natural, Physica e Hygiene, Trabalhos Manuaes e Exercicios Physicos".

A esse conhecimento autorizado agregavam-se outros dispositivos, dentre eles, um minucioso regulamento do ensino, trazendo um código disciplinar que normatizava comportamentos, estabelecia muitas obrigações para as crianças e muitos poderes para os agentes escolares, além de impor a obediência a preceitos higiênicos e aos valores morais preconizados, por exemplo.

O movimento de afirmação dessa nova cultura escolar revela, no entanto, os limites do projeto escolar republicano. Tome-se, por exemplo, a instalação de Grupos Escolares na Capital. Sua região central - planejada, limpa, considerada a cidade - recebeu imediatamente dois grupos escolares, no início do ano letivo de 1907, apenas dois meses após a reforma. Simbolicamente, o $1 .^{\circ}$ Grupo Escolar da capital (e do Estado de Minas) foi instalado no palacete do próprio Secretário do Interior e o $2 .^{\circ}$ Grupo Escolar ocupou um prédio desativado de um quartel da polícia. Também nessa região foi instalada, em 1909, uma Escola Infantil para atender as crianças de 0 a 6 anos. Da mesma forma, foi por essa região que se iniciou a construção dos suntuosos prédios para abrigar os grupos escolares, e o primeiro deles foi inaugurado em 1914, para o qual foi transferido o $1^{\circ}$ Grupo Escolar da capital, já com o nome de Barão do Rio Branco.

Por sua vez, a região periférica de Belo Horizonte - onde moravam as populações pobres, constituindo uma não-cidade, desorganizada e caótica ainda esperaria quase cinco anos até conhecer o seu primeiro Grupo Escolar e nesse tempo continuou contando com as escolas isoladas, que, como mostrou Luciano Mendes de Faria Filho, eram classificadas como "pardieiros". Somente em abril de 1911 é que foi instalado um Grupo Escolar em um bairro cujos moradores eram pobres, quando a região central já possuía quatro deles.

E o seu prédio nem de longe lembrava a suntuosidade prevista para os prédios do centro da cidade.

Ora, são exemplos dos limites a que se estendia o projeto educativo republicano em Belo Horizonte: ainda que a reforma de ensino primário tenha sido defendida sob o discurso de atender às crianças pobres, as atenções estiveram voltadas para a região central da cidade - organizada, monumental, que se queria cosmopolita e reservada às camadas economicamente mais elevadas: nela (e por ela) é que deveria se instituir uma nova forma escolar, que se queria também modelar, como a Capital. Assim, a primeira condição de matrícula de crianças pobres nos Grupos Escolares da região central era entrar na cidade, ser aceito e incluído em seu espaço educativo, incorporado aos seus ritmos. A presença dessas crianças nos três primeiros Grupos Escolares de 
Belo Horizonte trazia ares de legitimidade ao próprio projeto educativo que se implantava. Mas, periféricas, habitantes da não-cidade - portanto, não-cidadãos -, grande parte das crianças pobres ficou excluída da nova forma escolar que surgia. Nessa região, a precariedade das Escolas Isoladas continuava como tônica. Na cidade cindida, a propaganda republicana se fez com o reforço da exclusão.

Ancorada em pressupostos de uma decantada racionalidade científica, destacando-se sua sintonia com teorias racistas e higienistas que circulavam no País, a escola, em seu novo molde, foi projetada como instituição capaz de introjetar nas crianças maneiras julgadas superiores, modos considerados civilizados, orientando-as para assumir condutas inteiramente distintas daquelas que possuíam. Nesse movimento, os corpos das crianças tornaram-se alvo do investimento da escola, sendo colocado no centro das práticas educativas: constituí-lo, ou reconstituí-lo, racionalmente, tornou-se atribuição da escola.

Mas, mesmo esse investimento tinha limites claros: nem todos os corpos interessavam à escola. Os critérios para a constituição da população escolar também indicam o limite do projeto republicano de levar a educação a todos os cidadãos. O regulamento do ensino de 1911, por exemplo, excluiu do conceito de alunos "os doentes, affectados por molestias contagiosas incuraveis" e "os loucos". Esses, os corpos renegados pelo modelo escolar que se queria afirmar. Para eles, instituições especializadas, ou a exclusão.

Os corpos escolarizáveis seriam tomados como suporte de inscrição dos predicados esperados de um cidadão republicano, consagrando-se à escola a façanha de cultivá-los para neles plantar hábitos e condutas que os fizessem limpos, saudáveis, ordeiros, robustos - atributos de uma miragem estética. Tal façanha afeiçoa-se às pretensões educativas da Capital mineira, a cidade moderna construída como vitrina da República.

Adimensão da "educação physica", que compunha a tríade educativa pretendida com o novo modelo escolar, não se restringiria, assim, a uma disciplina escolar específica, como o emprego atual do termo pode fazer crer. Ao contrário, a cultura escolar, como um todo, deveria realizá-la, traduzindo-se em sentido alargado como cultivo dos corpos das crianças.

Ao penetrar nessa cultura, tendo como fontes, especialmente, os relatórios das diretoras e dos inspetores dos grupos escolares da capital, dos Secretários do Interior ${ }^{10} \mathrm{e}$, ainda, a legislação do ensino então em vigor ${ }^{11}$, foi

10 A "instrucção publica" era uma responsabilidade atribuída à então "Secretaria dos Negócios do Interior" Minas Gerais.

11 Todos os documentos consultados estão no Arquivo Público Mineiro, em Belo Horizonte. 
possível perceber que de muitas maneiras a escola procurou "tirar do corpo as impurezas que ofendiam vistas exigentes", frase lapidar de Graciliano Ramos. ${ }^{12}$ Práticas constitutivas dos corpos infantis podem ser percebidas já na arquitetura prevista para os prédios escolares e prosseguiam na organização e na ocupação dos lugares, na distribuição dos tempos escolares, nos programas de ensino, na obsessão pela higiene, na inspeção médica, nos rituais, dentre outros, e ainda nos muitos cuidados a eles dedicados pelas diretoras e professoras nas práticas educativas. Assim, preparar o lugar; desinfetar, limpar e inspecionar os corpos das crianças consideradas regeneráveis; renegar os corpos de outras, tidas por incapacitadas; impor hábitos higiênicos; disciplinar os bárbaros; estabelecer códigos de controle e punição; refinar sensibilidades, lapidando sentimentos, arrancando vícios, implantando civilidade, afinando a voz, ensinando o gosto, educando as mãos - são dispositivos que, em conjunto, revelam práticas escolares de constituição dos corpos das crianças.

Contudo, a mobilização desses dispositivos encontrou também na escola a "insubmissão estética" "13 das crianças. Ao controle, elas respondiam com transgressão, ludibriando pais, inspetores, diretoras e professoras. São mostras disso a recusa de muitas em ir para a escola, preferindo as ruas; as fugas, quando lá estavam; as indisciplinas e artimanhas quando lá permaneciam; as brincadeiras que levavam da rua para os espaços escolares, subvertendo usos previstos, criando maneiras de se apropriar deles. Os que fizeram a cultura escolar em Belo Horizonte experimentaram práticas em conflito.

O movimento de afirmação social da escola não ocorreu de forma harmônica e consensual, mas em meio a tensões estabelecidas com outras práticas culturais dos atores sociais. No caso mineiro, se a produção da necessidade da escola para civilizar as populações pobres e colocar o Estado nas trilhas da modernidade foi intensa, isso não significou imediata adesão da população. A escola não se impôs com facilidade. Exemplo é o fato de os pais não enviarem seus filhos e suas filhas para a escola porque precisavam deles e delas em pequenos trabalhos familiares; outro motivo era que muitas crianças estavam nas ruas da cidade, "em completa vadiagem", como registra um inspetor escolar. A baixa freqüência, um dos grandes obstáculos enfrentados pela escola pode configurar, também, a não-aceitação, simples e imediata, do saber legitimado pela escola.

Também os próprios agentes escolares estiveram envolvidos em relações de adesão e obediência, mas também de tensão e resistência, que reve-

12 RAMOS, G. Infância. 1977. p. 119.

13 Expressão de Pedro Nava, já citada antes para falar das práticas lúdicas das crianças na cidade. 
lam disputas de representações e conflitos de práticas que não se encaixavam no que estava previsto e determinado: mudanças parciais ou desobediência completa aos programas decretados pelo governo, com o privilégio de determinadas disciplinas e marginalização de outras; alteração na organização dos tempos escolares são exemplos de práticas comuns nos Grupos Escolares da capital.

A tensão resultante entre o movimento de afirmação social da escola e a resistência dos atores envolvidos expressa as contradições e os impasses experimentados no processo de organização e constituição de uma cultura escolar inserida, por sua vez, na própria constituição de uma cultura urbana, em Belo Horizonte, naquele momento.

Acompanhando esse movimento, destacou-se o enraizamento da "gymnastica" nas práticas escolares.

O advento dos Grupos Escolares, com a reforma do ensino primário de 1906, tornou possível a escolarização da "Gymnastica". Esse novo molde escolar foi determinante para a constituição paulatina de seu campo disciplinar. Para tanto concorreram, dentre outros motivos, a introdução do ensino seriado, com quatro anos de duração; a constituição de turmas com alunos de idade homogênea; a conformação e prescrição de um programa de ensino; a definição de horários específicos e a previsão de construção de espaços para a sua realização (ou a indicação de uso de outros espaços da escola, como os pátios) e, ainda, a produção de representações sempre positivas sobre sua participação na educação das crianças. Inclui também uma discussão inicial, que envolve os agentes escolares, sobre a necessidade de um professor(a) especificamente responsável pelo seu ensino.

A necessidade de sua presença na educação das crianças foi produzida e realçada nos sucessivos ordenamentos legais, e pode ser exemplificada com uma recomendação sempre presente, expressa aos diretores(as) e professores(as): "Não se descuide desta parte da educação das creanças na escola porque della depende desenvolvimento physico dos futuros cidadãos". Era também representada como fundamental para o "aperfeiçoamento dos sentidos humanos". Tais representações postas em circulação legitimam sua inserção na cultura escolar que se afirmava em Belo Horizonte.

Os programas escolares conformados legalmente para a Ginástica incluíam diversas práticas corporais precisas e sistematizadas de marcante caráter racional e higiênico, nas quais também pôde ser percebida a tentativa de realizar o que Guacira Lopes Louro chamou de "construção escolar das diferenças" entre meninos e meninas, que já foram objeto de investigação de Eustáquia Salvadora de Sousa em sua Tese. Inicialmente, foram prescritas marchas e evoluções militares, e a elas são paulatinamente acrescentadas as 
minuciosas séries de exercícios físicos segmentados para as partes do corpo (baseadas na Ginástica Sueca). Depois de realizadas tais séries, e como desfecho de uma "licção de ginástica", as crianças podiam "brincar em liberdade" no pátio, acompanhadas da professora, algo como uma compensação à racionalidade imposta pelos exercícios regulados. ${ }^{14}$

Se a "gymnastica" foi autorizada a participar da cultura escolar que se afirmava em Minas Gerais, o que pretendia-se com ela nas práticas escolares?

Dos documentos analisados podem-se extrair vestígios que indicam que o enraizamento da ginástica nos grupos escolares da Capital, e em Minas Gerais, nas duas primeiras décadas do século XX, foi orientado pelo primado da correção e constituição dos corpos - a pretensão imediata com a presença da ginástica nas práticas escolares esteve fortemente marcada pela crença na sua capacidade de endireitar e robustecer os corpos das crianças, tidos por disformes, desalinhados e raquíticos. A ginástica foi produzida como uma prática ortopédica.

No relato da diretora Ignacia F. Guimarães, do "Grupo Escolar Henrique Diniz", da Capital, encontra-se uma tradução contundente desse primado. Ao final do ano de 1915, analisando a prática de ginástica em seu grupo escolar, ela escreveu: "os resultados desses exercicios foram excellentes. Alumnos que, a principio, apresentavam posição incorreta e andar desgracioso, corrigiram-se em pouco tempo". ${ }^{15}$

Vários indícios desse primado puderam ser percebidos nos documentos investigados: a adoção do método sueco de ginástica (especialmente de suas proposições relativas à "boa atitude normal" das crianças) e da calistenia; o emprego utilitário da Ginástica na consolidação da nova ordem escolar nos Grupos Escolares de Belo Horizonte, usada como recurso higiênico para combater a fadiga escolar nas crianças; o seu tratamento como dispositivo disciplinar, para tentar controlar as crianças e impor-lhes comportamentos desejáveis; o seu uso como dispositivo de aculturação das crianças, especialmente filhos e filhas de famílias pobres, com a crença em sua capacidade de eliminar vícios contraídos em casa e na rua, tornando-se um meio útil para se chegar à "padronização dos comportamentos calcados no modo de vida urbano" que então se buscava; sua defesa como prática de regeneração e aperfeiçoamento da raça; sua homologia com os novos processos de organização do trabalho, submetendo o corpo das crianças a uma nova organização de tempo, de espaço,

14 De todo modo, esse tempo de "brincar em liberdade" é uma primeira referência à possibilidade de realização de brincadeiras no tempo destinado à ginástica, insinuando uma tênue aproximação a um caráter lúdico.

15 Secretaria do Interior, Relatórios dos Grupos Escolares, Arquivo Público Mineiro, SI 3597, 1916. Grifo do documento. 
de ordem, aos imperativos econômicos da higiene, produzindo uma sensibilidade corporal nas crianças para as novas exigências do trabalho industrial e da vida urbana.

Enfim, esses são exemplos que mostram que da presença da Ginástica no âmbito escolar esperava-se uma intervenção ortopédica, de correção e endireitamento dos corpos "esgrouvirados" das crianças - a ela a tarefa de desempená-los e colocá-los em "posição erecta e varonil"16, exigência do novo tempo, da nova civilização que se queria inaugurada já na própria tessitura racionalizada da capital de Minas Gerais.

Contudo, o movimento inicial de constituição do campo disciplinar da "gymnastica" nos grupos escolares de Belo Horizonte foi também marcado por impasses e precariedades. Inexistência de espaços físicos conforme previsto na legislação; reduzida (e até mesmo desconsiderada) participação na distribuição dos tempos escolares; secundarização de seu ensino em relação a outras cadeiras do programa; dúvidas entre sua obrigatoriedade ou facultatividade; professoras sentindo-se despreparadas e sem condições de ensiná-la. São essas algumas circunstâncias em que seu ensino esteve envolvido nos primeiros momentos de sua inserção escolar em Belo Horizonte, como relatam diretoras e inspetores.

Percepção contundente de precariedades como essas encontrou-se no registro do diretor da Escola Normal Modelo da Capital, que, uma década após a reforma de ensino de 1906, sintetizou sua opinião referindo-se à "gymnastica" como "lettra morta" do programa.

Não impedem de ver, contudo, o investimento de uma época em que os agentes escolares se lançaram sobre as crianças na tentativa de realizar a sua "educação physica", de cultivar seus corpos - foi esse investimento que provocou o enraizamento escolar da ginástica em Minas Gerais, particularmente em Belo Horizonte.

\section{REFERÊNCIAS}

BARBOSA, Ruy et al. Parecer e Projeto de Reforma do Ensino Primário n. 224, da Comissão de Instrucção da Camara Federal. Rio de Janeiro, 1882.

16 Termos de BARBOSA, R. et al. Parecer e Projeto de Reforma do Ensino Primário $n$. 224, da Comissão de Instrução da Camara Federal. Rio de Janeiro, 1882. 
Saúde, 1947.

BORGES , Vera Lúcia Abrão. A ideologia do caráter nacional da educação em Minas - Revista do Ensino (1925 - 1929 ). Campinas. Dissertação (Mestrado em Educação) Faculdade de Educação, Universidade de Campinas. 108 p.

CARDOSO SILVA, Vera Alice. Crônicas de Belo Horizonte. Varia Historia, Belo Horizonte, UFMG (FAFICH), n. 18, set. 1997.

CARVALHO, José Murilo. A construção da ordem: a elite política imperial; Teatro de Sombras: a política imperial. 2. ed. rev. Rio de Janeiro: Editora UFRJ, Relume-Dumará, 1996.

. A formação das almas: o imaginário da República no Brasil. 3. ed. São Paulo: Cia. das Letras, 1997.

. Os bestializados: o Rio de Janeiro e a República que não foi. 3. ed. São Paulo: Cia. das Letras, 1997.

CARVALHO, Marta M. Chagas. Quando a história da educação é a história da disciplina e da higienização das pessoas. In: FREITAS, Marcos Cezar (Org.). História social da infância no Brasil. São Paulo: Cortez, 1997a.

. História da Educação: notas sobre uma questão de fronteiras. Educação em Revista. Belo Horizonte, Autêntica/Faculdade de Educação da UFMG, n. 26, p. 5-15, dez. $1997 \mathrm{~b}$.

Por uma história cultural dos saberes escolares. CONGRESSO LUSOBRASILEIRO DE HISTÓRIA DA EDUCAÇÃO. 2., 1998, São Paulo. Anais... São Paulo: USP, Faculdade de Educação, fev. 1998.

Escola, analfabetismo e reformas da Instrução Pública na década de 1920. In: FARIA FILHO, Luciano M., LOPES, Eliane Marta; VEIGA, Cynthia Greive. 500 anos de educação no Brasil. No prelo.

; NUNES, Clarice. Historiografia da educação e fontes. Cadernos Anped, Porto Alegre, n. 5, p. 7-64, set. 1993.

; HANSEN, João Adolfo. Modelos culturais e representação: uma leitura de Roger Chartier. Varia Historia, Belo Horizonte, n. 16, p. 7-24, set. 1996.

CASTELlANI FILHO, Lino. Educação Física no Brasil: a história que não se conta. Campinas: Papirus, 1988.

CERTEAU, Michel de. A invenção do cotidiano - Artes de fazer. Petrópolis: Vozes, 1994.

. A escrita da história. Rio de Janeiro: Forense-Universitária, 1982.

. A cultura no plural. Campinas: Papirus, 1995. 
CHARTIER, Roger. A história cultural - Entre práticas e representações. Lisboa: Difel, 1990.

. O mundo como representação. Estudos Avançados, São Paulo, Instituto de Estudos Avançados, USP, v. 5, n. 11, jan./abr. 1991.

. A história hoje: dúvidas, desafios, propostas. Estudos Históricos, Rio de Janeiro, CPDOC, v. 7, n. 13, p. 97-114, 1994.

CHERVEL, André. História das disciplinas escolares. Teoria \& Educação, Porto Alegre, n. 2, p. 177-229, 1990.

DESAULNIERS, Julieta B. Ramos. Instituição e evolução da escolarização. Teoria \& Educação, Porto Alegre, n. 6, p. 97-104, 1992.

ESCOLANO, Augustín. Arquitetura como programa: espaço-escola e currículo. In: ESCOLANO, Augustín; VINÃO FRAGO, Antonio. Currículo, espaço e subjetividade: a arquitetura como programa. Tradução: Alfredo Veiga-Neto. Rio de Janeiro: DP\&A, 1998.

FARIA FILHO, Luciano Mendes de. Conhecimento e cultura na escola: uma abordagem histórica. In: DAYRELL, Juarez (Org.). Múltiplos olhares sobre educação e cultura. Belo Horizonte: Ed. da UFMG, 1995a.

. Dos pardieiros aos palácios: forma e cultura escolares em Belo Horizonte -1906/1918. São Paulo, 1996. Tese (Doutorado em Educação) - Faculdade de Educação, USP.

. Cultura e práticas escolares: escrita, aluno e corporeidade. Cadernos de Pesquisa, Fundação Carlos Chagas, n. 103, p. 136-149, mar. 1998.

FOUCAULT, Michel. Vigiar e punir. 7. ed. Rio de Janeiro: Vozes, 1989.

. Microfísica do poder. 8. ed. Rio de Janeiro: Graal, 1989.

FOURQUIN, Jean-Claude. Saberes escolares, imperativos didáticos e dinâmicas sociais. Teoria \& Educação, Porto Alegre, n. 5, p. 28-49, 1992.

Escola e cultura: as bases sociais e epistemológicas do conhecimeno escolar; tradução: Guacira Lopes Louro. Porto Alegre: Artes Médicas, 1993.

FREITAS, Marcos Cezar (Org.). História social da infância no Brasil. São Paulo: Cortez, 1997.

GOELLNER, Silvana V. O método francês e a educação física no Brasil: da caserna à escola. Porto Alegre, 1992. Dissertação (Mestrado em Educação) - Universidade Federal do Rio Grande do Sul.

HÉBRARD, Jean. A escolarização dos saberes elementares na época moderna. Teoria \& Educação, Porto Alegre, n. 2, p. 65-110, 1990. 
JULIÃO, Letícia. Belo Horizonte: itinerários da cidade moderna (1891-1920). Belo Horizonte, 1992. Dissertação (Mestrado em Ciência Política) - Faculdade de Filosofia e Ciências Humanas, Universidade Federal de Minas Gerais. 200 p.

LE GOFF, Jacques. História e memória. 4. ed. Campinas: Ed. da Unicamp, 1996.

LOPES, Eliane Marta T. A educação da mulher: a feminização do magistério. Teoria \& Educação, Porto Alegre, n. 4, p. 22-40, 1991.

Fontes documentais e categorias de análise para uma história da educação da mulher. Teoria \& Educação, Porto Alegre, n. 6, p. 105-114, 1992.

LOURO, Guacira L. Uma leitura da história da educação sob a perspectiva do gênero. Teoria \& Educação, Porto Alegre, n. 6, p. 53-67, 1992.

. Educação e gênero: a escola e a produção do feminino e do masculino. In: SILVA, L. H.; AZEVEDO, J. C. (Orgs.). Reestruturação curricular: teoria e prática no cotidiano da escola. Petrópolis: Vozes, 1995a.

Pedagogias da sexualidade. In: LOURO, Guacira L. (Org.). O corpo educado. Pedagogias da sexualidade. Belo Horizonte: Autêntica, 1999. p. 7-34.

MACLAREN, Peter. Rituais na escola: em direção a uma economia política de símbolos e gestos na educação. Petrópolis: Vozes, 1991.

MAIO, Marcos Chor; SANTOS, Ricardo Ventura (Orgs). Raça, ciência e sociedade. Rio de janeiro: Fiocruz/CCBB, 1996.

MARINHO, Inezil Penna. Sistemas e Métodos de Educação Física. 6. ed. São Paulo: Papelivros, [s/d].

NAVA, Pedro. Beira-Mar. 3. ed. Rio de Janeiro: Nova Fronteira, 1985. (Memórias, 4).

NOGUEIRA, Maria Alice. Educação, saber, produção em Marx e Engels. São Paulo, Cortez: Autores Associados, 1990.

NÓVOA, Antonio. Inovação e história da educação. Teoria \& Educação, Porto Alegre, n. 6, p. 210-220, 1992.

NUNES, Clarice. História da educação brasileira: novas abordagens de velhos problemas. Teoria \& Educação, Porto Alegre, n. 6, p. 151-182, 1992.

PENNA, Alícia Duarte. Belo Horizonte: um espaço infiel. Varia Historia, Belo Horizonte, n. 18, p. 101-121, set. 1997.

SCHWARCZ, Lilia Moritz. O espetáculo das raças: cientistas, instituições e questão racial no Brasil - 1870-1930. São Paulo: Cia. das Letras, 1993.

SENNETT, Richard. Carne e pedra. O corpo e a cidade na civilização ocidental. Rio de Janeiro: Record, 1997. 
SKIDMORE, Thomas E. Preto no branco: raça e nacionalidade no pensamento brasileiro. Rio de Janeiro: Paz e Terra, 1976.

SOARES, Carmen Lúcia. Educação Física: raízes européias e Brasil. São Paulo: Autores Associados, 1994.

. Imagens da educação no corpo: estudo a partir da ginástica francesa no século XIX. Campinas, 1996. Tese (Doutorado em Educação) - Faculdade de Educação, Universidade de Campinas.

SOUSA, Eustáquia Salvadora de. Meninos à marcha, meninas à sombra: a história da Educação Física em Belo Horizonte - 1897/1994. Campinas, 1994. Tese (Doutorado em Educação) - Faculdade de Educação, Universidade de Campinas.

SOUZA, Rosa de Fátima. Espaço da Educação e da civilização: origens dos Grupos Escolares no Brasil. In: SOUZA, Rosa Fátima; VALDEMARIN, Vera Teresa; ALMEIDA, Jane Soares (Orgs.). O legado educacional do século XIX. Araraquara: Unesp, Faculdade de Ciências e Letras, 1998.

. Templos de civilização: A implantação da escola primária graduada no Estado de São Paulo (1890-1910). São Paulo: Fundação Editora da Unesp, 1998.

THOMPSON, Paul. A voz do passado: história oral. Rio de Janeiro: Paz e Terra, 1992.

VARELA, Julia; ALVAREZ-URIA, Fernando. A maquinaria escolar. Teoria \& Educação, Porto Alegre, n. 6, p. 68-96, 1992.

VEIGA, Cynthia Greive. Cidadania e educação na trama da cidade: a construção de Belo Horizonte em fins do século XIX. Campinas, 1994. Tese (Doutorado em Educação) - Faculdade de Educação, Universidade de Campinas.

. Projetos urbanos e projetos escolares - aproximação na produção de representações de educação em fins do século XIX. Belo Horizonte: UFMG, Faculdade de Educação, 1997 (digitado).

; FARIA FILHO, Luciano M. Belo Horizonte: a escola e os processos educativos no movimento da cidade. Varia Historia, Belo Horizonte, n. 18, set. 1997.

VEYNE, Paul. Como se escreve a história. Brasília: UnB, 1992.

VIDAL, Diana G. Fontes visuais na história: significar uma peça. Varia Historia, Belo Horizonte, n. 13, p. 128-131, jun. 1994.

; GIRTZ, Silvina. O ensino da escrita e a conformação da modernidade escolar:

Brasil e Argentina, 1880-1940. Revista Brasileira de Educação. São Paulo: Anped, n. 8, p. 13-30, maio/jun./jul. 1998.

VIGARELLO, Georges. Panóplias corretoras. In: SANT'ANNA, Denise Bernuzzi (Org.). Políticas do corpo. São Paulo: Estação Liberdade, 1995. p. 21-38. 
VIÑAO FRAGO, Antonio. História da alfabetização versus história do pensamento, ou seja, da mente humana. Teoria \& Educação, Porto Alegre, n. 2, p. 124-135, 1990.

. Historia de la educatión e historia cultural: posibilidades, problemas, cuestiones. Revista Brasileira de Educação, São Paulo, n. 0, p. 63-82, set./dez. 1995.

Tiempos escolares, tiempos sociales. La distribución del tiempo y del trabajo en la enseñanza primaria en España (1838-1936). Barcelona: Anil, 1998.

. Do espaço escolar e da escola como lugar: propostas e questões. In: ESCOLANO, Augustín; VINÃO FRAGO, Antonio. Currículo, espaço e subjetividade: a arquitetura como programa. Tradução: Alfredo Veiga-Neto. Rio de Janeiro: DP\&A, 1998. 